\title{
HABIT MODIFICATION OF GEL GROWN PURE AND DOPED STRONTIUM TARTRATE CRYSTALS
}

Sindhu A.*, Gudennavar S. B.* and Bubbly S. G. ${ }^{*+}$

\section{ABSTRACT}

Pure and doped Strontium tartrate tetrahydrate single crystals were grown in silica gel. The growth features of these crystals with variation of parameters like specific gravity of gel, gel pH, acid concentration, concentration of feed solution and gel age were studied in defail.

\section{Introduction}

Crystal habit is controlled by many aspects of crystallization process and is directly related to how crystals grow and the driving force of crystallization process [Kurian K. V. et al. 1980]. External shapes of crystals depend not only on the crystal symmetry, but also on the growth conditions employed. In gel method the speed of crystal formation depends on gel density, concentration of reactant in the gel, concentration of reagents diffused into the gel, temperature, length of diffusion path etc.

* Post Graduate Department of Physics, Christ University, Bangalore - 560029

*† Corresponding author: Bubbly S.G. (e mail: bubbly.sg@christuniversity.in 
Growth of single crystals of strontium tartrate tetrahydrate and trihydrate has attracted many researchers [Patel and Arora 1976, 1977, Arora ef al. 2004 a, b, c, 2005 a, b] on account of their ferroelectric and non-linear optical characteristics based on their second harmonic generation. The crystals of strontium fartrate tetrahydrate grown in silica gel medium in pure form and doped with chromium, iron, cobalt, nickel, cadmium [Dennis and Henisch 1967, Rethinam et al 1993, 1994 a, b], vanadyl [Satyanarayana et al 1985], lead [Rahimkutty et al 2001], copper and barium [ $\mathrm{Viii}$ ef al 2005] have already been reported. But in the literature there is no systematic study of growth features with variation of growth parameters. Thus we intend to make a systematic study on the growth morphology, varying the growth parameters such as specific gravity of gel, gel pH, concentration of reactant in gel, concentration of feed solution etc. Since addition of dopants have a profound influence on growth kinetics and morphology, we have attempted to dope the crystals with lead and study the variation in growth features.

\section{Experimental}

As tartrates are sparingly soluble in water and decompose before melting, they cannot be grown by slow evaporation or melt technique. But the gel method is found to be a more promising crystal growth method. A test tube diffusion method [Henisch 1973] was employed to grow pure and doped strontium tartrate tetrahydrate crystals in the gel medium. The AR grade chemicals were used to grow the crystals. Crystallization was carried out in standard test fubes of dimensions $25 \mathrm{~mm}$ diameter and $200 \mathrm{~mm}$ length. Gels were prepared by mixing sodium meta silicate solution of appropriate specific gravity and tartaric acid of specific molarity so that the desired $\mathrm{pH}$ of the mixture could be obtained. The specific gravity, molarity and $\mathrm{pH}$ were varied between $1.02-1.07 \mathrm{~g} / \mathrm{cc}, 0.5-2 \mathrm{M}$ and $4-9$, respectively. After mixing, the solution was allowed to set. The gel was usually set within 2 to 6 days depending on the gel density, $\mathrm{pH}$ of gel solution and ambient temperature. After ensuring proper gel setting the feed solution $(1 \mathrm{M}, 0.25 \mathrm{M}, 0.5 \mathrm{M}, 0.75 \mathrm{M}$ and $2 \mathrm{M}$ solutions of $\mathrm{SrCl}_{2}$ and $0.35 \mathrm{M}, 0.4 \mathrm{M}, 0.5 \mathrm{M}$ and $1 \mathrm{M}$ solutions of $\left.\mathrm{Sr}\left(\mathrm{NO}_{3}\right)_{2}\right)$ was gently poured with the help of a pipette without disturbing the gel surface. The test fubes were kept closed to avoid evaporation of solution and contamination of impurities. The test tubes were kept undisturbed at room temperature. To grow $\mathrm{Pb}$ doped strontium tartrate tetrahydrate crystals an aqueous solution of Lead nitrate of varying concentrations, $0.1 \mathrm{M}, 0.2 \mathrm{M}$ and $0.01 \mathrm{M}$, was mixed with the top solution.

\section{Results and Discussion}

Different concentrations of reactants were used to determine the optimum condition for the growth of good quality single crystals. From the experiments, it was found that the minimum concentration of the tartaric acid for initiating the growth of 
crystals was $0.5 \mathrm{M}$. It was therefore, possible to grow crystals by varying the concentration of the tartaric acid in the range of $0.5-2 \mathrm{M}$. Best results were obtained using $7 M$ tartaric acid. For lower concentration, the quantity of tartaric acid should be more to obtain crystals of good geometrical shape.

The gel medium limits the diffusion of the reactants through the network. Increase in gel density, decreased the nucleation density, as greater the gel density, smaller is the pore size. The density of the gel-medium was varied between $1.02 \mathrm{~g} / \mathrm{cc}$ $1.07 \mathrm{~g} / \mathrm{cc}$. Well defined and transparent single crystals were obtained with sodium meta- silicate gel of specific gravity $1.03 \mathrm{~g} / \mathrm{cc}$.

The $\mathrm{pH}$ value played a significant role in the formation of the gel. Further it affected the morphology of the growing crystal. It was found that as $\mathrm{pH}$ was increased, the number of crystals decreased, but the size of crystals was increased. With both the feed solutions, best results were obtained for $\mathrm{pH} 8$.

The concentration of the feed solution was varied in the range of $0.1-3 \mathrm{M}$. In all the cases, the growth and morphology remained more or less the same. But still, Strontium nitrate was found to be better than Strontium chloride as feed solution. It was observed that the low concentration of supernatant solution is yielding good results. Best results were obtained at a concentration of $0.35 \mathrm{M}$ of $\mathrm{Sr}\left(\mathrm{NO}_{3}\right)_{2}$. The effect of parameters such gel density, concentration of tartaric acid and gel $\mathrm{pH}$ are summarized in Tables 1, 2 and 3, respectively.

Table 1: Variation of growth pattern with gel density

\begin{tabular}{|l|c|c|c|l|}
\hline SMS $(\mathrm{g} / \mathrm{cc})$ & $\begin{array}{c}\text { Tartaric } \\
\text { acid }(\mathrm{M})\end{array}$ & $\mathrm{pH}$ & $\begin{array}{c}\text { Feed } \\
\text { solution } \\
\mathrm{Sr}\left(\mathrm{NO}_{3}\right)_{2}(\mathrm{M})\end{array}$ & \multicolumn{1}{|c|}{ Growth pattern } \\
\hline 1.02 & 1 & 8 & 0.35 & $\begin{array}{l}\text { White precipitate of a few } \mathrm{cm} \text { length } \\
\text { and small crystallites }\end{array}$ \\
\hline 1.03 & 1 & 8 & 0.35 & $\begin{array}{l}3 \mathrm{~cm} \text { long white precipitate and } \\
\text { orthorhombic small crystals }\end{array}$ \\
\hline 1.035 & 1 & 8 & 0.35 & $\begin{array}{l}3 \mathrm{~cm} \text { long white precipitate and small } \\
\text { crystals of size } 1.5 \mathrm{~mm} \times 1 \mathrm{~mm} \times \\
0.5 \mathrm{~mm}\end{array}$ \\
\hline 1.04 & 1 & 8 & 0.35 & $\begin{array}{l}1 \mathrm{~cm} \text { long white precipitate with very } \\
\text { fine crystallites }\end{array}$ \\
\hline 1.07 & 1 & 8 & 0.35 & $1 \mathrm{~cm}$ long white precipitate \\
\hline
\end{tabular}


Table 2: Variation of growth pattern with concentration of tartaric acid

\begin{tabular}{|c|c|c|c|l|}
\hline $\mathrm{SMS}(\mathrm{g} / \mathrm{cc})$ & $\mathrm{pH}$ & $\begin{array}{c}\text { Feed } \\
\text { solution } \\
\mathrm{Sr}\left(\mathrm{NO}_{3}\right)_{2}(\mathrm{M})\end{array}$ & $\begin{array}{c}\text { Tartaric } \\
\text { acid }(\mathrm{M})\end{array}$ & \multicolumn{1}{|c|}{ Growth pattern } \\
\hline 1.03 & 8 & 0.5 & 0.5 & Leisgang rings, Small crystals \\
\hline 1.03 & 8 & 0.5 & 1 & Very small crystals \\
\hline 1.03 & 8 & 0.5 & 1.5 & Very fine crystallites \\
\hline 1.03 & 8 & 0.5 & 2 & Very fine crystallites \\
\hline
\end{tabular}

Table 3: Variation of growth parameters with gel $\mathrm{pH}$.

\begin{tabular}{|l|c|c|c|c|l|}
\hline SMS(g/cc) & $\begin{array}{c}\text { Tartaric } \\
\text { acid }(\mathrm{M})\end{array}$ & $\mathrm{pH}$ & $\begin{array}{c}\text { Feed } \\
\text { solution } \\
\mathrm{SrCl}_{2}(\mathrm{M})\end{array}$ & $\begin{array}{c}\text { Feed } \\
\text { solution } \\
\mathrm{rr}_{\left(\mathrm{NO}_{3}\right)_{2}(\mathrm{M})}\end{array}$ & \multicolumn{1}{|c|}{ Growth pattern } \\
\hline 1.03 & 1 & 8 & 0.5 & - & Small orthorhombic crystals \\
\hline 1.03 & 1 & 8 & - & 0.35 & Orthorhombohedral crystals \\
\hline 1.035 & 1 & 8 & 0.5 & - & Whiskers type growth \\
\hline 1.03 & 1 & 7 & 0.5 & & Very fine crystallites \\
\hline 1.03 & 1 & 7 & - & 0.35 & Very fine crystallites \\
\hline 1.03 & 1 & 6 & 0.5 & - & Fine crystallites \\
\hline 1.03 & 1 & 6 & - & 0.35 & Very fine crystallites \\
\hline 1.03 & 1 & 5 & 0.5 & - & $\begin{array}{l}\text { Gel breakage - cylindrical } \\
\text { growth }\end{array}$ \\
\hline 1.03 & 1 & 5 & - & 0.35 & Fine crystallites \\
\hline 1.03 & 1 & 4 & 0.5 & - & Sphenoidal crystals \\
\hline 1.03 & 1 & 4 & - & 0.35 & Fine crystallites \\
\hline
\end{tabular}

In order to study the effect of dopants on growth rate of the crystals, the feed solution was mixed with $0.01 \mathrm{M}, 0.02 \mathrm{M}$ and $0.1 \mathrm{M}$ solution of lead nitrate. It was observed that the addition of dopants reduced the nucleation rates considerably and reduced the growth rate of crystals. The effect of concentration variation of dopants is summarized in Table 4. 
Table 4: Variation of growth pattern with concentration of dopants

\begin{tabular}{|l|c|c|c|c|c|}
\hline SMS $(\mathrm{g} / \mathrm{cc})$ & Tartaric & $\mathrm{pH}$ & $\begin{array}{c}\text { Feed } \\
\text { solution } \\
\mathrm{Sr}\left(\mathrm{NO}_{3}\right)_{2}(\mathrm{M})\end{array}$ & $\begin{array}{c}\text { Dopant } \\
\mathrm{Pb}\left(\mathrm{NO}_{3}\right)_{2}(\mathrm{M})\end{array}$ & \multicolumn{1}{|c|}{ Growth pattern } \\
\hline 1.03 & 1 & 8 & 0.35 & 0.01 & $\begin{array}{l}3 \mathrm{~cm} \text { of thick precipitate; } \\
\text { small crystals }\end{array}$ \\
\hline 1.03 & 1 & 8 & 0.35 & 0.02 & $\begin{array}{l}4 \mathrm{~cm} \text { of thick precipitate; } \\
\text { fine crystals }\end{array}$ \\
\hline 1.03 & 1 & 8 & 0.35 & 0.1 & $\begin{array}{l}\text { 6cm of thick precipitate; } \\
\text { very fine crystallites }\end{array}$ \\
\hline
\end{tabular}

From the tables we see that with a suitable combination of gel density, concentration of tartaric acid, gel pH etc. it is possible to grow crystals of desired morphology and size. There were basically four habits [whiskers (Fig. (a)), orthorhombohedral (Fig. (b)), Leisgang ring (Fig. (c)) and sphenoidal (Fig. (d))] of the strontium tartrate tetrahydrate crystals grown in silica gel.

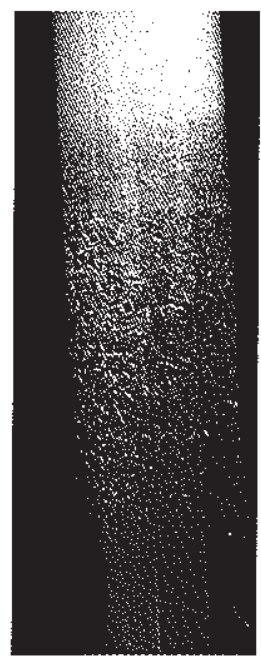

Fig. (a)

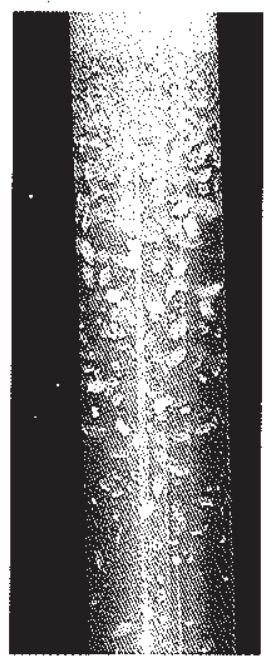

Fig. (b)

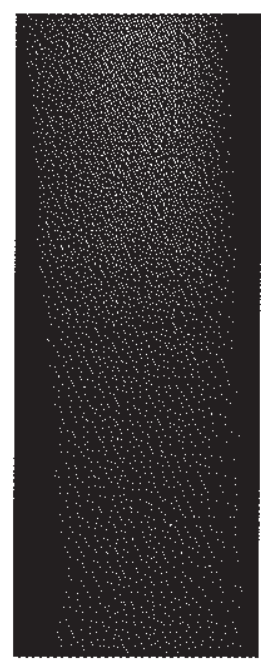

Fig. (c)

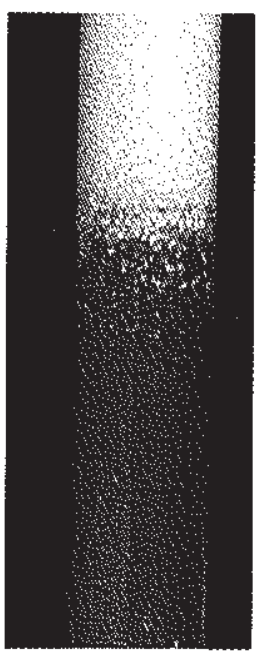

Fig. (d)

Fig. (a): Whiskers of STT with SMS of $1.035 \mathrm{~g} / \mathrm{cc}, 1 \mathrm{M}$ tartaric acid, $\mathrm{pH} 8$ and $0.5 \mathrm{M} \mathrm{SrCl}_{2}$

Fig. (b): Orthorhombic crystals of STT with SMS of $1.03 \mathrm{~g} / \mathrm{cc}$, $1 \mathrm{M}$ tartaric acid, $\mathrm{pH} 8$ and $0.35 \mathrm{M} \mathrm{Sr}\left(\mathrm{NO}_{3}\right)_{2}$ 
Fig. (c): Leisgang rings with SMS $1.03 \mathrm{~g} / \mathrm{cc}, 0.5 \mathrm{M}$ tartaric acid $\mathrm{pH} 8$ and $0.5 \mathrm{M} \mathrm{SrCl}_{2}$

Fig. (d): Sphenoids with SMS $1.03 \mathrm{~g} / \mathrm{cc}, 1 \mathrm{M}$ tartaric acid, $\mathrm{pH} 4$ and $0.5 \mathrm{M} \mathrm{SrCl}_{2}$

\section{Conclusions}

The peculiar effect of growth parameters on the crystallization and crystal habit of strontium tartrate tetrahydrate was studied systematically by varying the specific gravity of gel, concentration of tartaric acid, concentration of supernatant feed solution and $\mathrm{pH}$ of the gel. With a suitable combination of these conditions it is possible to grow crystals of desired morphology and size. There were basically four habits (whiskers, orthorhombohedral, Leisgang ring and sphenoidal) of the strontium tartrate tetrahydrate crystals grown in silica gel.

\section{References}

1. K. V. Kurian and M. A. Ityachen 1980, J. Mater. Sci. 15, 1724.

2. A. R. Patel and S. K. Arora 1976, J. Mater. Sci. 11, 843.

3. A. R. Patel and S. K. Arora 1977, J. Mater. Sci. 12, 2124.

4. S. K. Arora, V. Patel, A. Kothari and B. Amin 2004a, Crystal Growth and Design, 4, 343.

5. S. K. Arora, V. Patel, B. Amin and A. Kothari 2004b, Bull. Moter. Sci., 27, 141.

6. S. K. Arora, V. Patel and A. Kothari 2004c, Mater. Chem. Phys., 84, 323.

7. S. K. Arora, V. Patel, B. Chudasama and B. Amin 2005a, J. Cryst. Growth, 275, e657

8. S K. Arora, V. Patel, A. Kothari and B. Chudasama 2005b, J. Am. Ceram. Soc., 88, 3469.

9. J. Dennis and H. K. Henisch 1967, J. Electrochem. Soc., 114, 263.

10. F. J. Rethinam, D. Arivuoli, S. Ramasamy and P. Ramasamy 1993, Cryst. Res. Technol., 28, 861.

11. F. J. Rethinam, D. Arivuoli, S. Ramasamy and P. Ramasamy 1994a, Mater. Res. Bull., 29, 309.

12. F. J. Rethinam, S. Ramasamy, D. Arivuoli and P. Ramasamy 1994b, J. Mater. Sei. Lett., 13, 263.

13. N. Satyanarayana, K. Hariharan and S. Radhakrishna 1985, J. Mater. Sci., 20, 1993.

14. M. H. Rahimkutty, K. Rajendra Babu, K. Sreedharan Pillai, M. R. Sudarsana Kumar and C. M. K. Nair 2001, Bull. Mater. Sci, 24 (2), 249-252.

15. R. K. Viii, 8. Gowri and Sahaya Shajan X 2005, Indian J. Phys., 79, 1373.

16. Henisch H. K. 1973 Crystal growth in gels (University Park, PA: The Pennsylvania University Press). 